\title{
Morphological Classification of Idioms in English and Armenian
}

\author{
Anahit Hovhannisyan ${ }^{1 *}$, Rouzanna Ghazaryan ${ }^{2}$ \\ ${ }^{1}$ Shirak state University, Gyumri, Armenia \\ ${ }^{2}$ Gyumri, Armenia \\ Corresponding author. E-mail: a_hovhannisyan@mail.ru
}

Paper received 16.10.18; Revised 20.10.18; Accepted for publication 22.10.18.

\section{https://doi.org/10.31174/SEND-HS2018-184VI30-05}

\begin{abstract}
Idioms have been a subject of different investigations. They have been studied from different angles. However, it doesn't mean the problem has been studied to the core, or there is nothing to say about it anymore. The aim of this paper is to provide a general overview of the unique architecture of idioms in English and Armenian. The paper reports research findings from the contrastive study of typologically different languages. Are outlined the main structural patterns of idioms in source and target languages. Here are some findings: in English the final element of an idiom bears the main lexical meaning whereas in Armenian the head-verb regularly takes an initial position.
\end{abstract}

Keywords: contrastive study, morphological patterns, common and distinctive features, source and target languages.

Phrases remain as one of the fascinating linguistic phenomena drawing the attention of various scholars all over the world.

Many various lines have been used, and yet the place of phraseological units in the vocabulary and the boundaries of this level is one of the controversial issues of present-day linguistics ( Arnold: 155).

In the first step of our research we are aimed at revealing common and distinctive features of words and wordphraseological units, in the second step we are aimed at outlining allomorphic and isomorphic features of idioms and free syntactic combinations on the one hand, and idioms and idiom-sentences, on the other hand, and in the third step of our studies we go into contrastive analysis taking English as our frame of reference and viewing the native language in this case through the prism of a given inventory of categories.

Words and idioms. The appearance of well-known works on Russian phraseology by academician V.V. Vinogradov gave birth to an independent working-out of the problems of phraseology in the $20^{\text {th }}$ century. According to the scholar, phraseological units occupy an intermediate position between free word combinations and compound words. We depart from academician Vinogradov's statement as idioms take an intermediate position between words and sentences. What brings idioms closer to words? Some idioms are given birth by a single word and they are named words equivalent to idioms. For example: He is a selfy - old fox: often disapproving a person who is clever and able to get what they want by influencing or risking other people. (Oxford dictionary, p.583). The metaphorical shift takes place on the analogy of fox as an animal and a person.

As for the second common feature it lies at semantics ; single words functioning as language units of independent status with a definite referential (denotational) meaning and single words functioning as constituents of idiomatic constructions have the same denotational meaning. Similar to single words idiomatic constructions are not speech units as are not created in speech but are introduced into speech as ready-made units of language level. They both express one notion and function as one part of the sentence. Alongside with these common features they display some characteristics.

In idiomatic constructions word-constituents being combined with other words, undergo metaphorical change in their meanings never losing their status as a unit of language level: " The constituents of idioms keep their usual meanings while the combination as a whole possess a special meaning''(Arnold:159). Although equivalent to words in their function, idiom structurally can be decomposed into words while morphological decomposition of a word will yield to morphemes.

The main point of difference between a word and an idiom is the divisibility of the latter into separately structural elements which is contrasted to the structural integrity of words.

The closeness of single words and phraseological units is vividly expressed in parallel synonymous set, where each single word works with its corresponding synonymous set framed as an idiom: in Armenian viknkill ( single

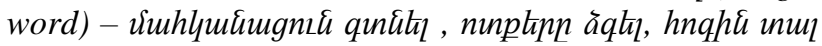
(idiomatic expression) in English to hurry( single word) and its parallel synonymic set to make haste (idiomatic expressions). However, the synonymic substitution of idiomatic phrases with single words would destroy the expressiveness of speech and would sound so dull and trivial. Thus, the function of idioms in speech is expressive and intensifying as compared to their one-word synonymous equivalents .

Compound words and phraseological units. There is a pressing need for criteria distinguishing idioms not only from words but from compound words as well.

Prof. Smirnitsky considers a phraseological unit to be similar to the word because of the idiomatic relationship between its part resulting in its semantic unity and permitting its introduction into speech as something complete (Smirnitsky:206). In compound words as well as in phrases the immediate constituents obtain integrity and structural cohesion that make them function in a sentence as a separate lexical unit (Arnold:60). In compound words the process of integration is much more advanced. Worthy of note are two important peculiarities distinguishing compounding in English from compounding in Armenian. Both immediate constituents of an English compound are free forms, i.e. they can be used as independent words with a distinct meaning of their own. The conditions of distribution will be different but from the sound pattern the same, except the stress : inkstand, motherland. The combining elements in Armenian are as a rule bound forms (2nlhp). In English where the first elements are bound forms ( politico- economical, Anglo- Saxon) are 
very rare and are coined on the neo-Latin pattern ( Arnold:64) The second feature is that the regular pattern for the English compounding is a two- stem compound. One more important feature: idiomatic phrases are molded by the same pattern as compounds are. This is a common formula for all languages. However, every language has its own means of compounding that are specific only for the given language and are governed by the inner laws of that language. This is an isomorphic feature characteristic of that language and is of great significance for contrastive studies. It follows that molding of idiomatic combinations can reveal also laws reigning within the components of phrases, relations between head and dependent elements and their distribution. How close are the semantic ties between the parts of phrases and free combinations?

All the scholars agree that free syntactic combinations and phrases represent one member of sentence and there are syntactical ties within the units of free and fixed phrases.

Although similar in their outer framing free syntactic combinations and phrases have some basic differences.

1. The referential meaning of constituents in free combinations is unchanged while in phrases the same constituent being combined with other words acquire quite a new metaphorical meaning: Cf. free combination to play with fire (in the sentence Children mustn't play with fire) the same lexical unit play in this combination is used with its common meaning " to do things for pleasure"( Oxford Dictionary: 1119) and the same play in the phrase "to play with fire" loses its referential meaning and means "to act in a way that it's not sensible and takes dangerous risks", Oxford Dictionary: 557).

2. Due to its referential meaning in free combinations (expressions) each element has a much greater semantic independence of the other; substitution is possible here. However, no substitution for idiomatic expression can be made without ruining the phrase and damaging its expressiveness, evaluative loading.

We have now come to further step of our analysis namely to sentence -phraseological units.

Sentence-lawn idioms as the term speaks itself, come from simple or multiple sentences and correspondingly are similar to them in their structure having one or two predications. Verb takes a central part in this construction and being intermediately located it shares a border with the subject (with the agent of an action) and with its verbal complements. However, sentence - lawn idioms possess emotional characteristics and are peppered with numerous stylistic devices.

What is needed for, in our case cross-lingual comparison is structural, i.e. taking form and not meaning as the starting point. Very often such formulas, formally identical to sentences are used as insertions into sentences: "Butter would not melt in his mouth".

Tackling the morphological classification of idiomatic expressions it should be noted that the following patterns are distinguished in contrastive languages according to part of speech modification.

Units of this type are noun equivalents and can be partly or completely idiomatic.

The classification below, both in native and foreign languages takes into consideration not only the type of component parts but also the functioning of the whole entity, thus tooth and nail is not functioning as a nominal but an adverbial unit because it serves to modify a verb (to fight tooth and nail) ( Arnold:149). Moreover, not every nominal phrase is used in all the syntactic functions possible for nouns, thus a bed of roses, is used only predicatively.

Idioms take many different forms and structures. The majority of the idioms of the phrase - type are verbal or nominal.

Idioms functioning like nouns in English:

$\mathrm{N}+\mathrm{N}$ : maiden name

$\mathrm{N}+$ 's $+\mathrm{N}$ : cat's paw; a baker's dozen

$\mathrm{N}+\mathrm{s}$ ' $+\mathrm{N}$ : ladies' room

$\mathrm{N}+\mathrm{of}+\mathrm{N}$ : a bed of roses; a mouth of Sundays

a) Common noun+ of + common noun: eye of a needle, kiss of peace

b) Common noun+ of + proper name:

The majotity of idioms of this type are patterned by means of biblical proper names and toponyms: lion of Judah, tower of Babylon, patience of Job, wisdom of Solomon.

c) a subtype of " noun + of + noun" is the pattern in which the main word (constituent) is repeated twice; the form in singular and the lather in plural, as God of Gods, the song of songs.

The same is true for Armenian but the English analytical genitive is rendered into Armenian synthetically with

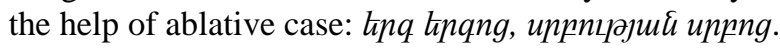

$\mathrm{N}+$ and $+\mathrm{N}$ : lord and master (husband)

$\mathrm{N}+\mathrm{A}$ : knight errant

$\mathrm{A}+\mathrm{N}$ : green room (reception room of a theatre); grey matter

$\mathrm{N}+$ subordinate clause: ships that pass in the night

With each of these classes a further subdivision is possible. The following patterns are not to be exhaustive and are given only the principal features of the types.

Idioms functioning like verbs in English

$\mathrm{V}+\mathrm{N}$ : to take advantage; to catch a straw; to speak BBC

The grammar centre of such units is the verb, the semantic centre in many cases is the nominal component. These units can be perfectly idiomatic as well as "to burn one's boats", "to take to the cleaners", to have a smoke"

$\mathrm{V}+$ postpositive: to give up, to lift heel against " to turn against"

$\mathrm{V}+$ and $+\mathrm{V}$ : to pick and choose

$\mathrm{V}+$ (one's) $+\mathrm{N}+($ preposition$)$ : to snap one's fingers at; to put one's food about

$\mathrm{V}+$ one $+\mathrm{N}$ : to give one the bird "to fire smb"

V+subordinate clause: to see how the land lies " to discover the state of affairs"

Some examples of idioms functioning like adjectives in English are given below

$\mathrm{A}+\mathrm{and}+\mathrm{A}$ : high and mighty

A+ as+A: cool as cucumber; poor as a church mouse, easy as $\mathrm{ABC}$

These units are equivalents of adverbs and have no grammatical centre. They can be partly or completely idiomatic, as cool as a cucumber (partly), bread and butter (completely).

as $+\mathrm{A}+\mathrm{as}+\mathrm{N}$ : as old as the hills, as mad as the hatter

Some combinations functioning like adverbs are made up of : 
$\mathrm{N}+\mathrm{N}$ : tooth and nail

Prep $+\mathrm{N}$ :by heart, of course, on the spot

Adv.+prep $+\mathrm{A}+\mathrm{N}$ : once in a blue moon

Prep $+\mathrm{N}++$ or $+\mathrm{N}$ : by book or by crook

Conj+ clause : before one can say Jack Robinson

The functional frequency of these patterns is great with neutral style and devoid of expressiveness.

Prep $+\mathrm{N}$, prep $+\mathrm{N}+$ prep, prep $+\mathrm{A}$, prep $+\mathrm{N}+$ conj.

Types are nearer to words and as a rule function in speech as adverbs: by heart, for good or as form words: by means of, in order that, etc. The units of these groups have no semantic centre and are established as onesummit unit . ( Arnold: 158)

Idioms functioning like preposition in English:

Prep $+\mathrm{N}+$ prep

It should be noted that the type is often but not always characterized by the absence of article: on the ground of , in consequence of (no article)

Idioms functioning like interjections:

These are mainly patterned as imperatives: Take your time, God bless you!

Idioms functioning like sentence in English:

I beg your pardon, How do you do? They differ from all the combinations so far discussed because they are not equivalent to words in distribution and are semantically analysable. Very often such formulas, formally identical to sentences are used only as insertions into other sentences : "You should know if the cap fits" ( the cap fits" " the statement is true”)

Idioms functioning like nouns in Armenia:

$\mathrm{N}+\mathrm{N}$ : nult huuul, dunhl huuwl

The last constituent in $\mathrm{N}+\mathrm{N}$ module can be patterned differently because of various case modifications:

Genitive case + noun: hnqnı huunnp, unjnıдh purdhई

Noun in accusative case + noun in dative case: q[nıhu

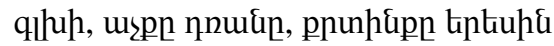

Noun in instrumental (qnnдhuluud) + noun : un々nц unıu, hugny ưun

Noun in ablative + noun : nunphg qinı u, utinfinhg ukpnı\&n

Noun+ noun in locative case: ănılp ennıú, Gnıunp ălnıu

$\mathrm{N}+$ and+N: unnıp nı nựng , guul nı lnull

Noun in:

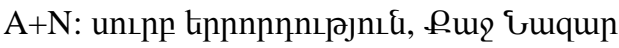

Idioms functioning like adjectives:

A + coordinative + A as: hutnf nı lnul, duun nı utio

$\mathrm{A}+\mathrm{N}$ pattern prevails in Armenian , comprising a separate subgroup with specific relations governing between a noun and an adjective, this module in its turn can have two structural modifications:

a) Noun+ adjective, being distributed prepositively in relation to an adjective a noun takes a definite article as: jtiqnid duin

b) Noun + adjective; being left-headed the noun in this formulae appears in ablative case ( pugunulyuuhg), thus pertaining objective (humpuujhu) relation to the adjective (relates to an adjective as an object): urphg hutnf, nunphg ptipl, uluwąqlinhg huting:

The quantative leaders of the group are verbal idioms.

They are constituted by head-noun + pospositive : prp nuul, zud đưud, ălıp hưưup
Idioms functioning as verbs: In these idioms the head member is a verb that can be expressed either by finite or non-finite verbs. In the case of finite verbs predicative relation gains a governing status and due to this property an idiomatic expression functions as a separate part of a

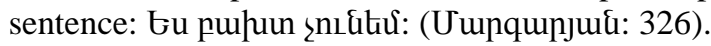

While being patterned with a non finite constituent it loses its specific predicative characteristics and the whole idiomatic entity merely acquires verbal notion . For ex-

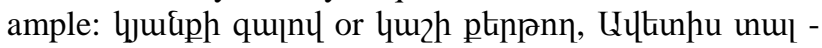
ulthinkl

Idioms functioning like sentences:

In these sentences the axis is a verb with its various conjugated manifestations:

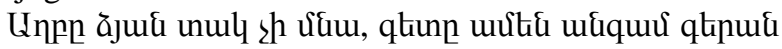
sh ptiph .

These idioms regularly originated from simple or multiple sentences and consequently can be structurally of two types: simple - sentence idioms and multiplesentence idioms. They are generally asydentic by their structure.

Thus, idioms mirror the national spirit of a language and are always rich in cultural connotation and national flavor. Word-formation of idioms is patterned according to a definite universal, dictated by the word building norms of the given language. In Armenian the final element of an idiom operates as a key backbone of the combination. Bearing the main lexical loading the key element can be morphologically patterned by nominal and verbal parts of speech. In contrast to Armenian an English head -verb constituent regularly takes an initial position in an idiomatic phrase. In all noun phrases models in Armenian the last constituent of the combination is regularly expressed by a noun functioning also as a head member. Moreover, Armenian is rich in noun + noun universals as Armenian has a highly developed case system and the dependent noun in noun + noun model can take different case inflections. In English idioms the last word is not subjected to morphological changes. Idioms are semantically word like units but structurally syntactic units.

The lack of prepositional phrases in Armenian is compensated by postpositive phrases. Two - membered idiomatic constructions are of great functional occurrence in contrastive languages. In both languages phrases are heterogynous units being expressed by single words fixed word combinations and sentences.

In Armenia out of $100 \%$ of idioms $85 \%$ are of verbal character, and $15 \%$ are nominal. In spite of great precentage divergence both verbal and nominal idioms are the result of semantic shift of word combinations.

There are distinguished two -membered, threemembered, four-memberd, five- membered idioms where the summit is a verb combined with a noun.

Presentation. The primary aim of my presentation is to describe idioms from cross-linguistic perspective with a particular focus on their structural modeling.

I begin with a general outline of idioms and wind up with contrastive analysis. The whole aim of contrastive analysis is to slow what languages have in common and where they differ.

Words and idioms. The appearance of well-known works on Russian phraseology by academician V.V. 
Binogradov gave birth to an independent working-out of the problems of phraseology in the $20^{\text {th }}$ century. According to the scholar, phraseological units occupy an intermediate position between free word combinations and compound words. We depart from academician Vinagradov's statement as idioms can be expressed by a single word too.

Idioms take an intermediate position between words and sentences. What brings idioms closer to words? Some idioms are given birth by a single word and they are named word -idioms or words equivalent to idioms. For example: He is a selfy - old fox: often disapproving a person who is clever and able to get what they want by influencing or risking other people. ( Oxford dictionary,p.583).

The metaphorical shift takes place on the analogy of fox as an animal and a person.

As for the second common feature it lies at semantics ; single words functioning as language units of independent status with a definite referential (denotational) meaning and single words functioning as constituents of idiomatic constructions have the same denotational meaning. Similar to single words idiomatic constructions are not speech units as are not created in speech but are introduced into speech as ready-made units of language level. They both express one notion and function as one part of the sentence. Alongside with these common features they display some characteristics.

In idiomatic constructions word-constituents being combined with other words, undergo metaphorical change in their meanings but never losing their word unit status of language level; " The constituents of idioms keep their usual meanings while the combination as a whole possess a special meaning." ( Arnold, p. 159) Morphological division of a word will yield to morphemes while phraseological division will bring to words.

The main point of difference between a word and an idiom is the divisibility of the latter into separately structural elements which is contrasted to the structural integrity of words.

The closeness of single words and phraseological units $^{2}$ is vividly expressed in parralel synonymous set, where each single word works parralelly with its corresponding synonymous team framed as an idiom: in Ar-

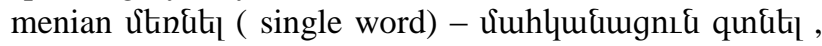
nunptinp unkt, hnqhई unul ( idiomatic expressions ) in English to hurry( single word) and its parralel synonymic set to make haste( idiomatic expressions).

The function of idioms is speech is expressive and intensifying as compared to their one-word synonymous equivalents .

Compound words and phraseological units. There is a pressing need for criteria distinguishing idioms not only from words but from compound words as well.

Prof. Smirintsky considers a phraseological unit to be similar to the word because of the idiomatic relationship between its part resulting in its semantic unity and permitting its introduction into speech as something complete (Лексикология английского языка, Москва , 1956, стр. 206). In compound words as well as in phrases the immediate constituents obtain integrity and structural cohesion that make them function in a sentence as a separate lexical unit (Arnold, 60). In compound words the process of integration is much more advanced. Worthy of note are two important peculiarities distinguishing compounding in English from compounding in Armenian. Both immediate constituents of an English compound are free forms, i.e they can be used as independent words with a distinct meaning of their own. The conditions of distribution will be different but from the sound pattern the same, except the stress : inkstand, motherland. The combining elements in Armenian are as a rule bound forms (2nlhp). In English where the first elements are bound forms ( politicoeconomical, Anglo- Saxon) are very rare and are coined on the neo-Latin pattern (Arnold , 64) The second feature is that the regular pattern for the English compounding is a two- stem compound. One more important feature : idiomatic phrases are molded by the same pattern as compounds are. This is a common formulae for all languages. However, every language has its own means of compounding that are specific only for the given language and are governed by the inner laws of that language. This is an isomorphic feature characterized of that language and which is of great significance for contrastive studies. It follows that molding of idiomatic combinations can reveal also laws reigning within the components of phrases, relations between head and dependent elements and their distribution. How close are the semantic ties between the parts of phrases and free combinations?

All the scholars agree that free syntactic combinations and phrases represent one member of sentence and there are syntactical ties within the units of free and fixed phrases.

Although similar in their outer framing free syntactic combinations and phrases have some basic differences.

3 . The referential meaning of constituents in free combinations is unchanged while in phrases the same constituent being combined with other words acquire quite a new metaphorical meaning: Cf. free combination to play with fire ( in the sentence Children mustn't play with fire) the same lexical unit play in this combination is used with its common meaning " to do things for pleasure"( Oxford dict. 1119) and the same play in the phrase "to play with fire" loses its referential meaning and means "to act in a way that its not sensible and takes dangerous risks", Oxf. Dic. 557).

4. Due to its referential meaning in free combinations (expressions) each element has a much greater semantic independence of the other ; substitution is possible here. However, no substitution for idiomatic expression can be made without ruining the phrase and damaging its expressiveness, evaluative loading.

We have now come to further step of our analyses namely to sentence - phraseological units.

Sentence -lawn idioms as the term speaks itself, come from simple or multiple sentences and corresponding are similar to them in their structure having one or two predications. Verb takes a central part in this construction and being intermediately located it shares a border with the subject ( with the agent of an action) and with its verbal complements. However, sentence - lawn idioms possess emotional characteristics and are peppered with numerous stylistic devices .

What is needed for, in our case cross-lingual comparison is structural, ie. taking form and not meaning as the starting point . 
Tackling the morphological classification of idiomatic expressions it should be noted that the following patterns are distinguished in contrastive languages according to part of speech modification.

Units of this type are noun equivalents and can be partly or completely idiomatic.

The classification below, both in native and foreign languages takes into consideration only the type of component parts but also the functioning of the whole entity, thus tooth and nail is not functioning as a nominal but an adverbial unit because it serves to modify a verb ( to fight tooth and nail)( Arnold,149). Moreover, not every nominal phrase is used in all the syntactic functions possible for nouns, thus a bed of roses, is used only predicatively .

Summary. Idioms mirror the national spirit of a language and are always rich in cultural connotation and national flavor. Word-building of idioms is patterned according to a definite universal, dictated by the word building norms of the given language. In Armenian the final element of an idiom operates as a key backbone of the combination. Bearing the main lexical loading the key element can be morphologically patterned by nominal and verbal parts of speech. In contrast to Armenian an English head -verb constituent regularly takes an initial position in an idiomatic phrase. In all noun phrases models in Armenian the last constituent of the combination is regularly expressed by a noun functioning also as a head member. Moreover, Armenian is rich in noun+noun universals as Armenian has a highly developed case system and the dependent noun in noun+noun model can take different case inflections.

The lack of prepositional phrases in Armenian is compensated by postpositive phrases. Two -membered idiomatic constructions are of great functional occurrence in contrastive languages. In both languages phrases are heterogynous units being expressed by single words fixed word combinations and sentences.

\section{REFERENCES}

1. I.V. Arnold The English Word. Moscow, Vysschaya Shkola, 4. В.В. Виноградов Основные понятия русской фразеологии 1973.

2. Makkai Adam Idiom Structure in English, The Hague, Mouton, 1972

3. A.S. Hornby. Oxford Advanced Learner's Dictionary of Current English, Oxford University Press, как лингвистической дисциплины, Москва, 1964.

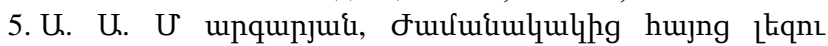

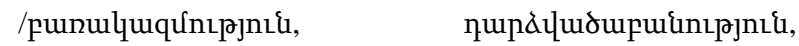

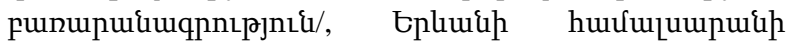
hpuunupulı̨nıpjnı\{, Epluwi 1990: 